Article

\title{
Aqueous Gold Nanoparticles Generated by AC and Pulse-Power-Driven Plasma Jet
}

\author{
Pengcheng Xie ${ }^{1,2}$, Yi Qi ${ }^{1}$, Ruixue Wang ${ }^{1, *}$, Jina $\mathrm{Wu}^{3}$ and Xiaosen $\mathrm{Li}^{3, *}$ \\ 1 College of Mechanical and Electrical Engineering, Beijing University of Chemical Technology, Beijing 100029, \\ China; xiepc@mail.buct.edu.cn (P.X.); 2018210368@mail.buct.edu.cn (Y.Q.) \\ 2 State Key Laboratory of Organic-Inorganic Composites, Beijing University of Chemical Technology, \\ Beijing 100029, China \\ 3 State Key Laboratory of NBC Protection for Civilian, Beijing 102205, China; wujina09@163.com \\ * Correspondence: wrx@mail.buct.edu.cn (R.W.); momentday@126.com (X.L.)
}

Received: 31 August 2019; Accepted: 16 October 2019; Published: 18 October 2019

\begin{abstract}
In this study, we developed a simple-to-use approach based on an atmospheric pressure plasma jet to synthesize aqueous Au nanoparticles (AuNP). Special attention was paid to the different reaction dynamics and AuNP properties under AC and pulse-power-driven plasma jets (A-Jet and P-Jet, respectively). The morphology of the AuNP, optical emissions, and chemical reactions were analyzed. Further, a copper mesh was placed above the reaction cell to evaluate the role of electrons and neutral species reduction. A visible color change was observed after the A-Jet treatment for $30 \mathrm{~s}$, while it took $3 \mathrm{~min}$ for the P-Jet. The A-Jet treatment presented a much higher AuNP growth rate and a smaller AuNP diameter compared with the P-Jet treatment. Further analysis revealed an increase in chemical concentrations $\left(\mathrm{Cl}^{-}\right.$and $\left.\mathrm{H}_{2} \mathrm{O}_{2}\right)$ and liquid conductivity after plasma treatment, with a higher increased amplitude for the A-Jet case. Moreover, the electrons alone had little effect on AuNP generation, while neutral species showed a clear $\mathrm{Au}^{+}$reduction effect, and a unique coupling effect between both reactions was observed. The different reaction dynamics between the A-Jet and P-Jet were attributed to their different local heating effects and different discharge power during the reaction.
\end{abstract}

Keywords: aqueous gold nanoparticles; AC-powered plasma jet; pulse-powered plasma jet; gold nanoparticle generation; chemical reactions

\section{Introduction}

High-quality gold nanoparticles (AuNPs) play a crucial role in numerous fields, including catalysis, optoelectronics, medical imaging, and sensors [1,2]. Highly purified surfactant-free AuNPs are very important because residual components limit their applications. Numerous methods, including chemical reduction, biosynthesis, and laser ablation, have been reported for AuNP synthesis [3,4]. However, the high cost associated with the synthesis of monodisperse size and shape-controlled nanoparticles and the use of toxic reducing agents makes them undesirable [5].

Plasma-liquid interaction has received much attention as a novel nanoparticle generation approach [6]. The electron energy generated by atmospheric pressure plasma can reach up to a few electron volts; thus, it is able to initiate the direct reduction of metal ions in the gas-liquid interface. Other oxidative species, such as $\mathrm{OH} \cdot$ and $\mathrm{H}_{2} \mathrm{O}_{2}$, can have possible reactions with chloroauric acid $\left[\mathrm{AuCl}_{x}(\mathrm{OH})_{4-x}\right]^{-}$to form AuNP because $\mathrm{AuCl}^{-} \mathrm{x}$ has a strong oxidation ability [7]. Various types of plasma can be applied to produce nanoparticles [8]: (1) remote plasma or plasma jet: gas discharge between an electrode and the electrolyte surface, (2) direct plasma: discharge between the electrodes. Microplasma, as one of the remote plasmas, usually works as a cathode electrode [9]. The high-energy 
electrons are believed to be responsible for initiating AuNP growth [10]. Normally, the electrolytic cell is driven by a DC power supply with several $\mathrm{kV}$, and a large resistor $(100 \mathrm{k} \Omega$ ) is connected to the circuit to limit the discharge current. Most of the power is consumed on the resistor instead of discharge. In addition, due to the small diameter of microplasma (hundreds of micrometers), the production rate is limited. In direct plasma, two metallic electrodes were immersed in liquids [11]. By applying radio frequency $(\mathrm{RF})$ power, metallic nanoparticles are produced through the erosion of a metallic electrode exposed to plasma. The particle size is determined by the quenching rate of the surrounding water.

Recently, the continuous synthesis of colloidal gold nanoparticles by introducing liquid droplets into a plasma reactor has been proposed $[12,13]$. The picoliter reactor volume and droplet effect result in a high synthesis rate. However, the ability to scale-up the reactor might make this technology more practical. Ionic liquids have a very low vapor pressure and thus can operate at a low pressure where traditional large-sized processing plasmas can be applied [14]. Although there is no need for additional surfactant to stabilize the synthesized NPs, it is difficult to change their surface function. Most importantly, specific metal salts or ionic liquids are required due to the low solubility of many metal salts in ionic salts [15].

Atmospheric pressure plasma, working at room temperature, has drawn an immense amount of interest due to it being easy to scale up, its low cost, and its compact size [16-18]. A plasma jet, generated in open air rather than in confined chambers, can be used for direct treatment without the limitation of the object's size [19]. However, the treatment area of single plasma is small (less than $1 \mathrm{~cm}^{2}$ ) due to its inherent structure [20]. One convenient method is to form a jet array by grouping a number of individual plasma jets units together. Although the interaction mechanisms between individual jets require further investigation, a 2D jet array with 45 single jets has been successfully implemented to form a large treatment area [21]. The scale-up ability of plasma jets makes them practical for further industrial application.

In this study, we developed a one-step approach based on an atmospheric pressure plasma jet that directly interacts with liquids to generate aqueous AuNPs. By applying the plasma jet above the liquid surface, the AuNP can be produced by plasma-liquid interaction. Different from the microplasma mentioned above, there is no secondary electrode needed. In addition, the treatment area of the plasma jet can be enlarged by grouping multiply plasma jets together, which provides the possibility for industrial application. The different reaction dynamics and AuNP properties were compared with AC and pulse-power-driven plasma jets (A-Jet and P-Jet, respectively). The plasma-induced chemistry was studied by monitoring different chemical concentrations $\left(\mathrm{Cl}^{-}, \mathrm{H}_{2} \mathrm{O}_{2}\right.$, and $\left.\mathrm{NO}_{3}\right)$, the $\mathrm{pH}$ value, and the conductivity of the liquid during reaction processes. The role of electrons and neutral species for $\mathrm{Au}^{+}$reduction was analyzed by isolating these two factors into different reaction cells. Finally, the chemical reactions in the liquid by A-Jet and P-Jet were analyzed to explain the synthesis mechanisms involved in the A-Jet and the P-Jet.

\section{Materials and Methods}

In order to synthesize aqueous AuNPs, an atmospheric pressure plasma jet was placed $1 \mathrm{~cm}$ above an aqueous solution mixed with $\mathrm{HAuCl}_{4}$ and sodium citrate (total volume: $4 \mathrm{~mL}$ ). The plasma jet was constructed with a typical needle-ring electrode structure, the details of which can be found in reference [22]. A hollow stainless-steel tube was inserted into a quartz tube (inner diameter: $1.5 \mathrm{~mm}$, wall thickness: $0.1 \mathrm{~mm}$, length: $150 \mathrm{~mm}$ ), working as a high-voltage electrode. Copper tape with a width of $10 \mathrm{~mm}$ and a thickness of $180 \mu \mathrm{m}$ was wrapped around the quartz tube surface and worked as a ground electrode. $\mathrm{HAuCl}_{4}$ and sodium citrate were purchased from Sinopharm and were used without further purification. Once the plasma jet was ignited, high-energy electrons, reactive species, and UV were generated in the gas phase. These species subsequently went through the plasma-liquid interface to the bulk liquid. In the liquid region, the reduction of $\mathrm{Au}^{+}$into $\mathrm{Au}^{0}$ occurred, and $\mathrm{AuNPs}$ started to grow with the existence of the stabilizer (sodium citrate). Due to the high recombination rate of reactive species, only long-lived species (such as $\mathrm{H}_{2} \mathrm{O}_{2}, \mathrm{OH}-, \mathrm{NO}^{-}{ }_{2}, \mathrm{NO}^{-}{ }_{3}$ ) penetrated into 
the liquid. At the same time, the color of the $\mathrm{HAuCl}_{4}$ solution turned gradually from light yellow to pink, which indicated the formation of AuNP. After several seconds or minutes (depending on power supply) of the plasma jet treatment, the solution containing AuNP was collected.

The plasma jet was powered either by an AC power supply (Nanjing Suman Plasma Technology, CTP-2000K, Nanjing, China) or a pulsed power supply (Xi'an Smart Maple Electronic Technology, HVP-22P, Xi'an, China), and the discharge parameters were verified. Research-grade Ar gas (99.999\%) with a gas flow rate of $2 \mathrm{slm}$ (standard liter per minute) was used as the working gas. Once the plasma was ignited, the high-energy electrons that cascaded into the liquid solution were responsible for the initiation of AuNP growth. The schematic diagram of the plasma AuNP synthesis system is shown in Figure 1.

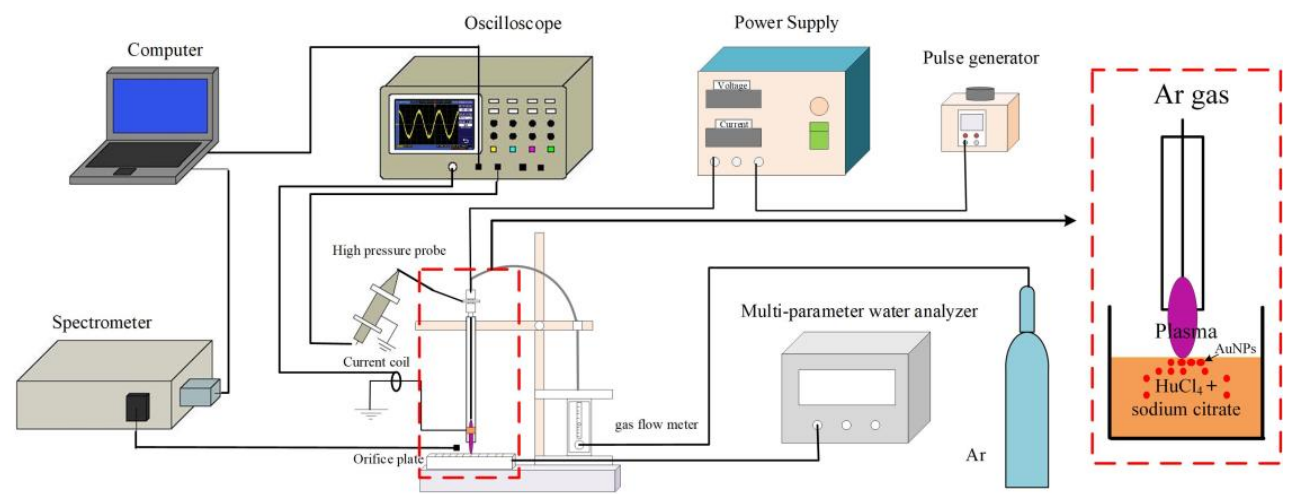

Figure 1. A schematic diagram of the plasma jet setup used for AuNP synthesis (inset shows enlarged diagram of plasma jet-liquid system).

The voltage and current characteristics were monitored by a high-voltage probe (Tektronix, P6015A, 1000:1, OR, USA) and a current probe (Pearson, model4100, 1 V/A) through a digital oscilloscope (Lecory WR204Xi, NYC, USA), respectively. The input power was calculated by the voltage-charge Lissajous method. A small capacitor with a capacitance of $1000 \mu \mathrm{F}$ was connected to the plasma jet ground electrode. The area $(A)$ enclosed by the power voltage, and the capacitor charge $(\mathrm{Q})$ was calculated. The input power $(P)$ was determined by

$$
P=f A,
$$

where $f$ is the pulse frequency.

A fiber optic cable was placed near the exit nozzle of the plasma jet to guide the light emission to the spectrometer (Ocean optics, Maya 2000 pro, FL, USA). Visible images of the as-synthesized AuNPs were captured by a digital SLR camera (Nikon D3200, Tkyo, Japan) coupled with a zoom lens (Nikkor, S-line, Nikon, Tkyo, Japan) with an exposure time of $0.5 \mathrm{~ms}$. The AuNPs were characterized by an ultraviolet-visible absorption spectrometer (IMPLEN Nanophotometr N60, MUC, Germany) in the wavelength range from 200 to $900 \mathrm{~nm}$. The size and shape distribution of the AuNPs was analyzed by a transmission electron microscope (TEM, TECNAIF30, OR, USA). A selected area electron diffraction (SAED) device coupled with the TEM was used to identify the crystal structure of the AuNPs.

The concentration of $\mathrm{Cl}^{-}$was measured by a water quality analyzer (Leici DZS-708, Shanghai, China). For $\mathrm{Cl}^{-}$measurement, the measuring electrode and reference electrode were immersed in a $0.001 \mathrm{~mol} / \mathrm{L} \mathrm{KCl}$ standard solution for $2 \mathrm{~h}$. $\mathrm{KCl}$ solutions with five gradients (100, 10, 1, 0.1, and $0.01 \mathrm{mmol} / \mathrm{L}$ ) were used for $\mathrm{Cl}^{-}$calibration. After each measurement, the electrodes were rinsed with deionized water to reduce the experimental error. The conductivity and $\mathrm{pH}$ value of the samples were measured by a conductivity meter (Leici TM-03 Pen-shaped conductivity meter, Shanghai China) and a pH meter (Leici PHSJ-3F, Shanghai, China), respectively. A hydrogen peroxide kit (LOHAND Test Strips Series 0-25 mg/L, Hangzhou, China) measured the concentration of hydrogen peroxide. 


\section{Results}

\subsection{Characterization of A-Jet and P-Jet}

Figure 2 represents the typical characteristics of A-Jet by measuring the voltage-current waveform, the calculated Lissajous figure, and the discharge image. During discharge, the applied voltage and frequency were kept consistently as $6.8 \mathrm{kV}$ and $90 \mathrm{kHz}$, respectively. The discharge occurred at both voltage rise and fall times during one discharge period, as shown in Figure 2a. There were several small current peaks followed by the main current peak at pulse rise and fall times, which confirmed a filamentary discharge mode in our condition (inset image). The development of a filamentary micro-discharge can be divided into three stages [23]: (1) pre-breakdown stage with negative charge accumulation, (2) ionization wave propagation towards the cathode, and (3) discharge filament bridged the gap, and a bright plasma channel is formed. To calculate the discharge power during discharge, a $100 \mu \mathrm{F}$ capacitor was series-connected in the circuit. The obtained Lissajous figure is shown in Figure $2 \mathrm{~b}$. The average power is equal to the product of the repetition frequency and the energy in a discharge period. So, the discharge power was calculated as $30.1 \mathrm{~W}$. The input power of the AC power supply was $68.1 \mathrm{~W}$; thus, the power efficiency was $45 \%$.
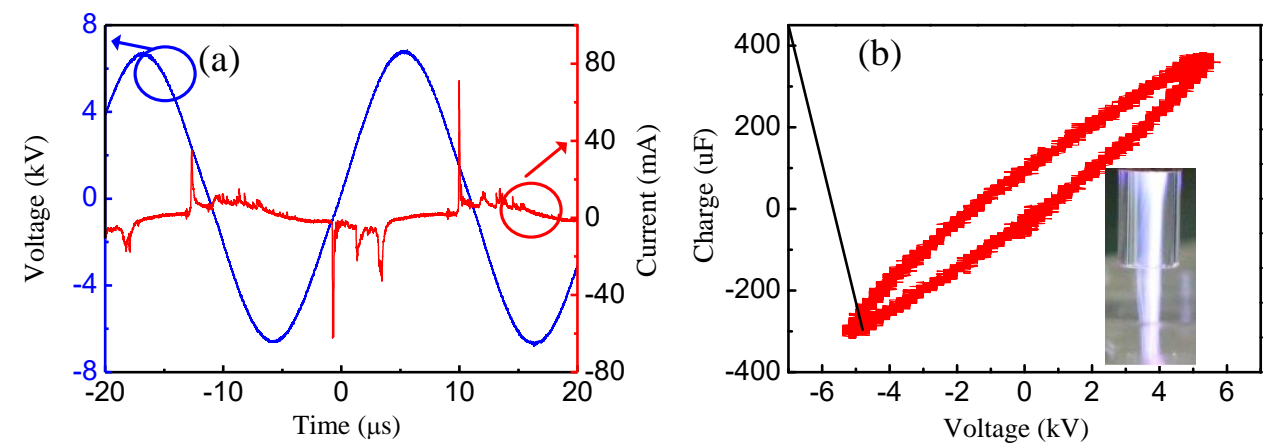

Figure 2. (a) Voltage and current discharge waveforms and (b) the corresponding Lissajous figure (The inset shows discharge image of A-Jet).

Different from the AC power supply, pulsed power supply with rapid pulse rise time provides high reduced electric field intensity $(\mathrm{E} / \mathrm{N})$ to accelerate electrons. In a pulsed discharge mode, high energy electrons are believed to ionize the gas to generate secondary electrons instead of depending on space ionization [24], so, the discharge is more spatially uniform, and the gas temperature is much lower in P-Jet compared to A-Jet. Figure 3 shows the typical waveforms of applied voltage, plasma current, discharge image, and consumed energy during one pulse duration. The discharge power was set as follows: a pulse rise and fall time of $50 \mathrm{~ns}$, a pulse duration time of $5 \mu \mathrm{s}$, and a pulse frequency of $8 \mathrm{kHz}$. One can see that the amplitudes of applied voltage and plasma current of the pulsed plasma jet were $8.5 \mathrm{kV}$ and $0.2 \mathrm{~A}$, respectively (Figure $3 \mathrm{a}$ ), with bipolar plasma current behavior. The instantaneous power consumption was $2.2 \mathrm{~kW}$, and the energy consumption during one pulse duration was $2.34 \mathrm{~mJ}$, respectively (Figure $3 \mathrm{~b}$ ). With an applied frequency of $8 \mathrm{kHz}$ in this case, the energy power consumption was $16.4 \mathrm{~W}$, which was much lower than that of the A-Jet (30.1 W). Compared to A-Jet, the discharge of P-Jet was much gentler and more homogenous, as shown in the inset image. 

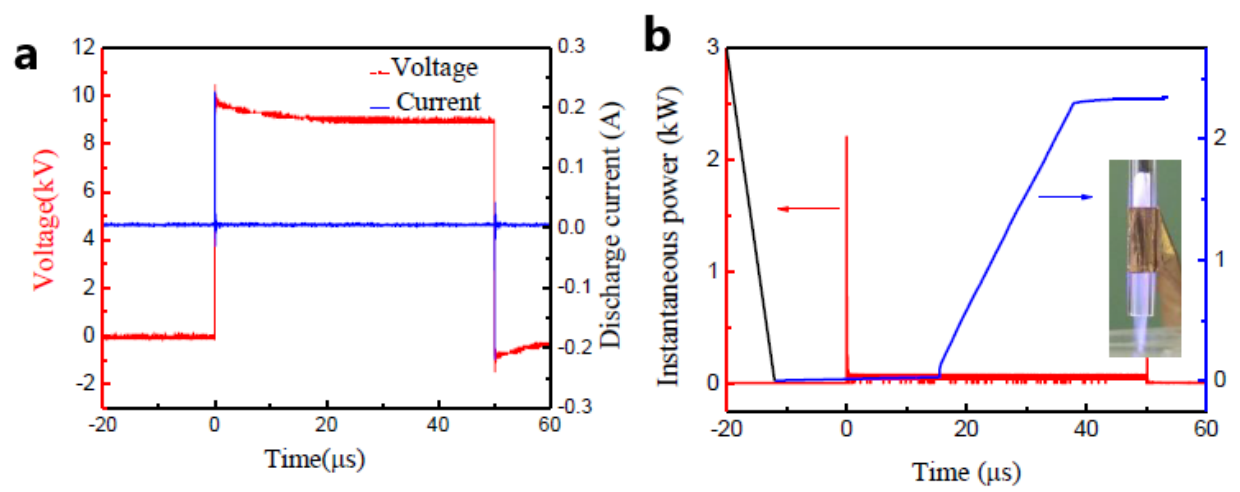

Figure 3. (a) Voltage and current discharge waveforms and (b) instantaneous power and energy waveforms of the P-Jet (the inset shows the discharge image of P-Jet).

\subsection{Synthesis of AuNP by A-Jet and P-Jet}

To generate AuNP, $1 \mathrm{~mL} \mathrm{HAuCl}_{4}(1.214 \mathrm{mM})$ and $3 \mathrm{~mL}$ sodium citrate $(34 \mathrm{mM})$ solutions were mixed together and treated with the A-Jet for different times. The time dependence of AuNP generation was studied first. As shown in Figure 4a, with a plasma jet treatment of $30 \mathrm{~s}$, the mixture solution changed from a shallow yellow to a dark violet, confirming the generation of AuNPs. As the plasma treatment time increased, the solution gradually became a red color. The shift in color was basically due to light absorption, depending on the particle size. When the size of the nanoparticles decreased, smaller wavelengths would be absorbed, and, so, a red color would be reflected. The absorption peak showed a similar trend: the absorption peak shifted towards lower wavelengths as the process time increased (Figure $4 \mathrm{~b}$ ). The absorption peaks were centered at 584, 566, and $535 \mathrm{~nm}$ for different plasma processing times of 30,60, and $90 \mathrm{~s}$, respectively. As the plasma treatment time increased to $120 \mathrm{~s}$, the absorption peak intensity stopped increasing, and the central absorption peak shifted towards higher wavelengths. This phenomenon was more obvious when the plasma processing time increased to $150 \mathrm{~s}$, at which time the central absorption peak increased to $545 \mathrm{~nm}$, and the peak width became wider. This indicated that after $90 \mathrm{~s}$, the $\mathrm{Au}^{+}$in the solution was totally consumed and AuNP began to aggregate. After $90 \mathrm{~s}$ of reaction, the synthesized AuNPs were isolated from the solution by centrifugation for $20 \mathrm{~min}$ at $1 \times 10^{4} \mathrm{rad} / \mathrm{min}$ and dried overnight at room temperature. A total of $9 \mathrm{mg}$ of AuNP was collected, and the formation rate was calculated as $0.4 \mathrm{mg} / \mathrm{s}$.
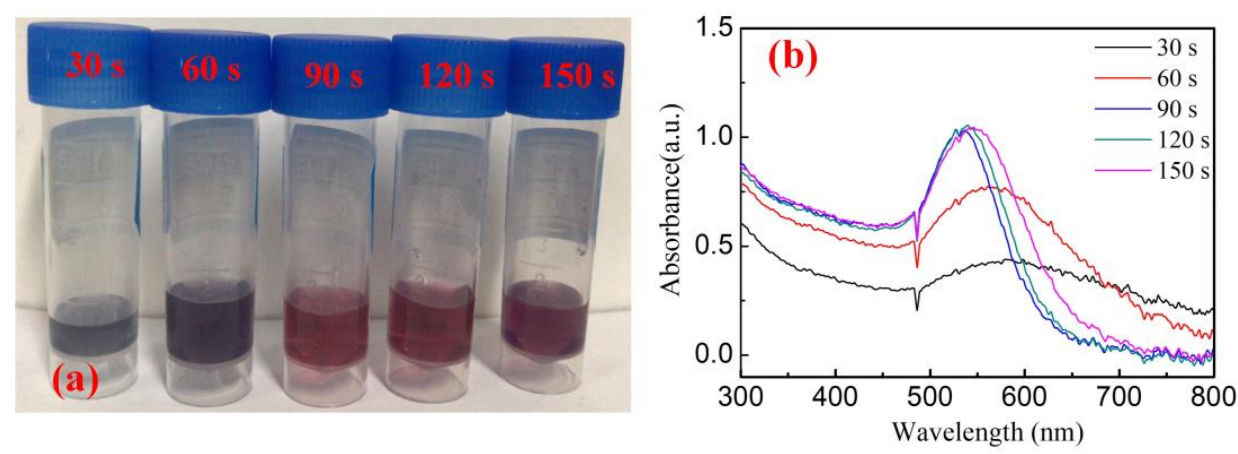

Figure 4. (a) Photos and (b) UV-Vis absorption spectra of AuNP for process times of 30, 60, 90, 120, and $150 \mathrm{~s}$.

With variations in the $\mathrm{HAuCl}_{4}$ /sodium citrate ratio, the absorption peaks of AuNP also changed (Figure 5). The central absorption peak position shifted to lower wavelengths with decreasing of the $\mathrm{HAuCl}_{4} /$ sodium citrate ratio. This "blue shift" of the peak indicated a decrease in the average nanoparticle size as the sodium citrate volume increased. This was understandable since the sodium 
citrate acted as a stabilizer as well as a reducing agent. In addition, the absorption peak intensity decreased as the sodium citrate volume increased due to fewer Au seeds provided by $\mathrm{HAuCl}_{4}$. $\mathrm{A}$ higher volume of sodium citrate led to more Au seeds and prevented the aggregation of AuNPs [25]. This was further confirmed by a broad distribution of UV-Vis absorption spectra with a very small volume of sodium citrate. The TEM images (Figure $6 a-c$ ) showed that the AuNP were generally of a range of shapes (spherical, cylindrical, and hexagon). The average diameters of the synthesized AuNPs were $18.2 \pm 9.0,32.9 \pm 14.1$, and $180.6 \pm 20.5 \mathrm{~nm}$ with $\mathrm{HAuCl}_{4} /$ sodium citrate ratios of 1:3, 1:1.75, and 1:0.3 (Figure 6a-c), respectively. The size distribution of the synthesized AuNPs measured by TEM was consistent with the UV-Vis spectra results (Figure 5), which confirmed that the higher sodium citrate concentration reduced the AuNP diameters. The dotted rings in the SAED pattern in Figure $6 \mathrm{~d}$ suggest that these AuNP had a pronounced crystal structure. The $d$-spacing of the rings suggests that the dotted rings represented the Bragg reflection of the [111], [200], [220], and [222] crustal planes, indicating a face-centered cubic (fcc) crystal structure. In addition, the high-resolution TEM (HRTEM) image of one typical single AuNP (Figure 5e) showed a crystal lattice fringe spacing of 0.236 nm, corresponding to the [111] lattice planes of the AuNP.

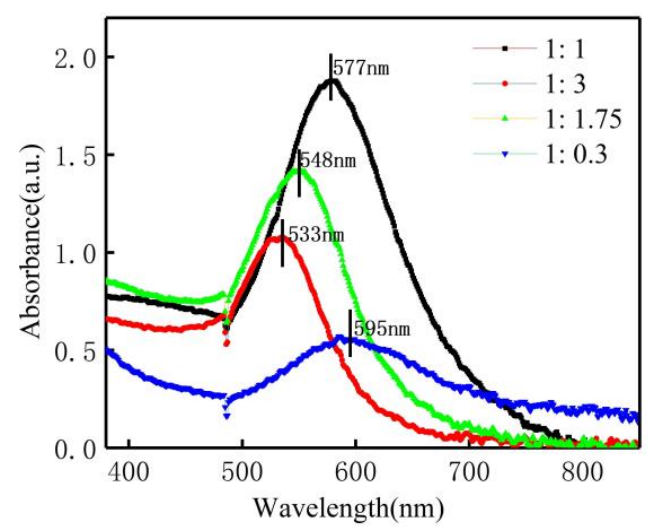

Figure 5. UV-Vis absorption spectra of AuNP for different $\mathrm{HAuCl}_{4} /$ sodium citrate ratios: (a) 1:1, (b) 1:3, (c) 1:1.75, and (d) 1:0.3. The total volume was kept at $40 \mathrm{~mL}$, and the plasma treatment time was $90 \mathrm{~s}$.
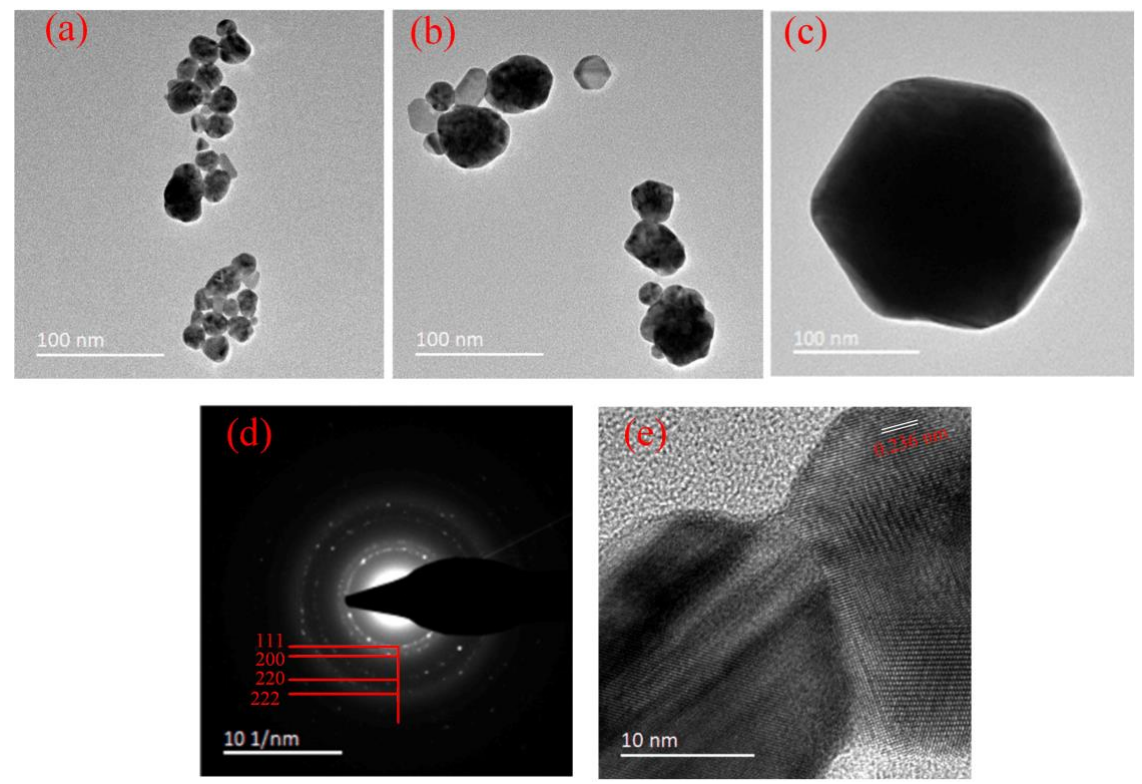

Figure 6. TEM images with different $\mathrm{HAuCl}_{4} /$ sodium citrate ratios: (a) 1:3, (b) 1:1.75, and (c) 1:0.3. (d) Selected area electron diffraction (SAED) pattern of an ensemble of AuNP, and (e) image of a typical single crystal of AuNP. 
Unlike the A-Jet case, the mixture solution did not change colors until 3 min of pulse plasma treatment $\left(\mathrm{HAuCl}_{4}\right.$ /sodium citrate ratio of 1:3). Further, the solution presented a brick-red color after $3 \mathrm{~min}$ of reaction and seemed cloudy (Figure 7a). Accordingly, the UV-Vis absorption peak was centered at $590 \mathrm{~nm}$, which confirmed a large AuNP diameter (Figure 7b). As the pulsed plasma treatment time increased, the UV-Vis spectra shifted to a lower wavelength (582 $\mathrm{nm}$ at $7 \mathrm{~min}$ ). The further increase of reaction time resulted in decreased absorption peak intensity and a broad absorption peak width (indicating a broad size distribution). After $7 \mathrm{~min}$, the $\mathrm{Au}^{+}$in the solution was totally consumed and AuNP began to aggregate. The generated AuNP were collected after 7 min reaction, and the formation rate was calculated as $9.5 \mu \mathrm{g} / \mathrm{s}$. Comparing the reactions initiated by the A-Jet and the P-Jet, the following differences were found: (1) the AuNP generation rate by the A-Jet was much faster than that of the P-Jet; (2) the AuNP size distribution was narrower in the A-Jet case; and (3) the AuNP size control range was broader in the A-Jet case. These differences were due to the different power consumption rates and different chemical reaction pathways introduced by the A-Jet and the P-Jet, which is well explained in the next section.
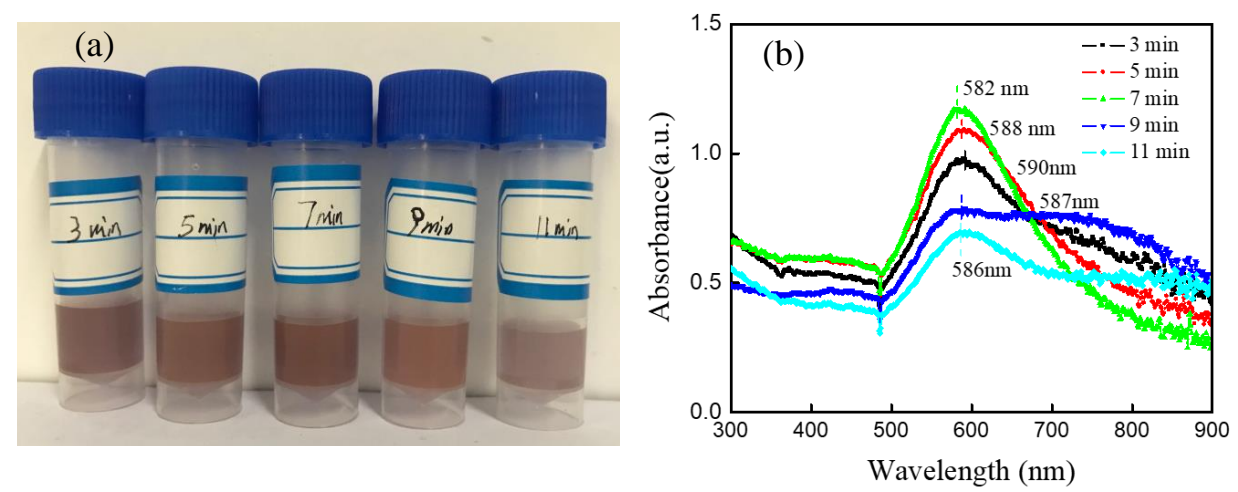

Figure 7. (a) Photos and (b) UV-Vis absorption spectra of AuNP for process times of 3, 5, 7, 9, and 11 min under P-Jet treatment (pulse frequency: $8 \mathrm{kHz}$, voltage: $8 \mathrm{kV}, \mathrm{HAuCl}_{4} /$ sodium citrate ratio of 1:3).

The TEM images of AuNP produced with a $\mathrm{HAuCl}_{4} /$ sodium citrate ratio of 1:3 for 7 min are shown in Figure 8. As shown in Figure 8a, the AuNP also presented a broad range of shapes, including spheres and polygons, and had an average diameter of $82.5 \pm 21.5 \mathrm{~nm}$. The dotted rings in the SAED pattern in Figure 8b represent the Bragg reflection of the [111], [200], [220], [222], and [420] crystal planes, indicating an fcc crystal structure. The HRTEM image of one typical single AuNP (Figure 8c) showed a crystal lattice fringe spacing of $0.204 \mathrm{~nm}$ (corresponding to the [200] lattice planes), which confirmed the crystallinity of the particles.
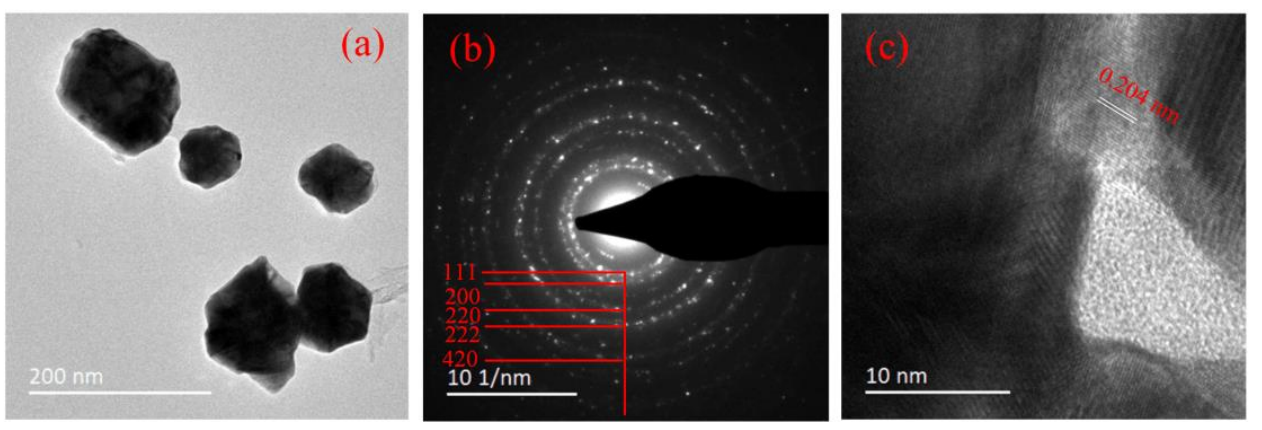

Figure 8. (a) TEM images of AuNP produced with a $\mathrm{HAuCl}_{4} /$ sodium citrate ratio of 1:3 with pulsed plasma treatment for $7 \mathrm{~min}$. (b) SAED pattern of an ensemble of AuNP. (c) high-resolution TEM (HRTEM) image of a typical single crystal of AuNP. 
As the diameter of synthesized AuNP increased with the decrease of sodium citrate concentration, and with $\mathrm{HAuCl}_{4} /$ sodium citrate ratio of 1:3, the average diameter of particle size was $82.5 \pm 21.5 \mathrm{~nm}$. So, there was no need to change the $\mathrm{HAuCl}_{4} /$ sodium citrate ratio as we did in A-Jet. Instead, the pulse repetition frequency was varied. Figure 9 shows that the intensity of the UV-Vis absorption peaks varied with the changes in pulse frequency. With the increase of pulse frequency, the UV-Vis absorption peak presented a blue shift, and the peak intensity increased. The increase of pulse frequency enhanced the input energy, thus corresponding to a higher AuNP generation rate.

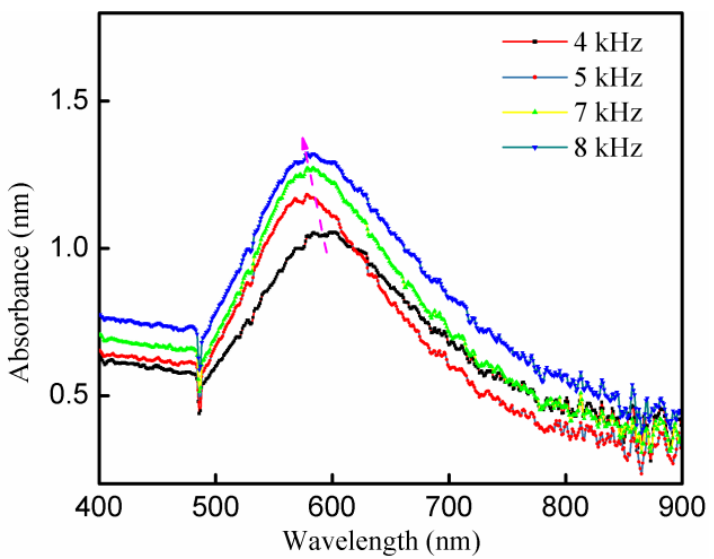

Figure 9. UV-Vis absorption spectra of AuNP under different pulse frequencies (applied voltage: $8.4 \mathrm{kV}$, treatment time: $7 \mathrm{~min}, \mathrm{HAuCl}_{4} /$ sodium citrate ratio of 1:3).

Tables 1 and 2 summarized the influence of variation of experimental parameters on AuNP properties by A-Jet and P-Jet, respectively. The particle sizes and shapes were obtained by TEM images of the synthesized AuNP. For the particle size distribution, around 100 particles were measured, and their average particle size was calculated. The AuNP with spherical, cylindrical, and hexagon shapes were found in all cases, confirming that these parameters had a little influence on particle shape. In other words, it was very difficult to control particle shape in our system. However, the particle diameters changed. For time-dependence, A-Jet and P-Jet showed a similar tendency. The UV-Vis absorption peak first decreased then increased with a plasma treatment time increase. In the first stage, a loose self-assembly of small Au nanoclusters formed coarse particles and disassembled into small nanoparticles at a low $\mathrm{pH}$ value. With the decrease of the $\mathrm{AuHCl}_{4} /$ sodium citrate ratio, the UV-Vis absorption peak showed "red shift", and particle size increased in A-Jet. It was interesting to see that the diameter of AuNP in A-Jet and P-Jet was $18.2 \pm 9.0 \mathrm{~nm}$ and $82.5 \pm 21.5 \mathrm{~nm}$ at $\mathrm{AuHCl}_{4} / \mathrm{sodium}$ citrate ratio of 1:3, indicating smaller AuNP were produced with A-Jet. A further decrease in sodium citrate ratio concentration would induce a larger particle size. So, it was hard to generate AuNP with a smaller size with P-Jet. That was why the variation of the $\mathrm{AuHCl}_{4} /$ sodium citrate ratio was not conducted in the P-Jet case. Instead, we changed the pulse repetition frequency and found that although the UV-Vis spectra peak moved to a lower wavelength, the particle diameter did not change too much if we compared it to the A-Jet case. 
Table 1. Summarize of AuNP properties treated by A-Jet.

\begin{tabular}{|c|c|c|c|c|c|}
\hline \multirow[b]{2}{*}{ Parameters } & & \multicolumn{4}{|c|}{ A-Jet } \\
\hline & & $\begin{array}{l}\text { Wavelength } \\
\text { (nm) }\end{array}$ & $\begin{array}{c}\text { Absorbance } \\
\text { (a.u.) }\end{array}$ & $\begin{array}{c}\text { Average Size } \\
\text { (nm) }\end{array}$ & Particles Type \\
\hline \multirow{5}{*}{$\begin{array}{l}\text { Time } \\
(\mathrm{s})\end{array}$} & 30 & 584 & 0.437 & - & - \\
\hline & 60 & 566 & 0.772 & - & - \\
\hline & 90 & 535 & 1.028 & $20.3 \pm 12.2$ & Spherical, cylindrical, hexagon \\
\hline & 120 & 541 & 1.053 & $27.4 \pm 10.4$ & Spherical, cylindrical, hexagon \\
\hline & 150 & 545 & 1.046 & - & - \\
\hline \multirow{4}{*}{$\begin{array}{l}\mathrm{AuHCl}_{4} / \text { Sodium } \\
\text { citrate ratio }\end{array}$} & $1: 1$ & 577 & 1.877 & - & \\
\hline & $1: 3$ & 533 & 1.072 & $18.2 \pm 9.0$ & Spherical, cylindrical, hexagon \\
\hline & $1: 1.75$ & 548 & 1.410 & $32.9 \pm 14.1$ & Spherical, cylindrical, hexagon \\
\hline & $1: 0.3$ & 595 & 0.550 & $180.6 \pm 20.5$ & Spherical, cylindrical, hexagon \\
\hline
\end{tabular}

Table 2. Summarize of AuNP properties treated by P-Jet.

\begin{tabular}{|c|c|c|c|c|c|}
\hline \multirow{2}{*}{ Parameters } & & \multicolumn{4}{|c|}{ P-Jet } \\
\hline & & $\begin{array}{l}\text { Wavelength } \\
(\mathrm{nm})\end{array}$ & $\begin{array}{l}\text { Absorbance } \\
\text { (a.u.) }\end{array}$ & $\begin{array}{c}\text { Average Size } \\
\text { (nm) }\end{array}$ & Particles Type \\
\hline \multirow{5}{*}{$\begin{array}{l}\text { Time } \\
(\min )\end{array}$} & 3 & 590 & 0.977 & - & - \\
\hline & 5 & 588 & 1.087 & - & - \\
\hline & 7 & 582 & 1.167 & $81.2 \pm 19.2$ & Spherical, cylindrical, hexagon \\
\hline & 9 & 587 & 0.779 & $100.2 \pm 20.3$ & Spherical, cylindrical, hexagon \\
\hline & 11 & 586 & 0.694 & $95.3 \pm 29.8$ & Spherical, cylindrical, hexagon \\
\hline \multirow{4}{*}{$\begin{array}{l}\mathrm{AuHCl}_{4} / \text { Sodium } \\
\text { citrate ratio }\end{array}$} & $1: 1$ & 594 & 1.923 & - & - \\
\hline & $1: 3$ & 582 & 1.167 & $82.5 \pm 21.5$ & Spherical, cylindrical, hexagon \\
\hline & $1: 1.75$ & 589 & 1.285 & - & $1-$ \\
\hline & $1: 0.3$ & 603 & 0.716 & - & - \\
\hline
\end{tabular}

\subsection{Plasma-Induced Chemistry Involved in A-Jet and P-Jet}

To explain the mechanism involved in A-Jet and P-Jet AuNP synthesis, optical emission spectroscopy was used to investigate the active species generated in the plasma jet. As shown in Figure 10, $\mathrm{OH}$. emission at 306-309 $\mathrm{nm}$ and $\mathrm{N}_{2}$ second positive system $\left(C^{3} \Pi_{\mu}-B^{3} \Pi_{g}\right)$ at $337,353,380$, and $405 \mathrm{~nm}$ were clearly observable in both cases; however, the peak intensity in the A-Jet case was much higher than in the P-Jet case. Similar Ar emissions from 656 to $850 \mathrm{~nm}$ presented in both cases and the intensity of these emissions were close. Near the gas-liquid interface, the dissociative electron attachment of $\mathrm{H}_{2} \mathrm{O}$ formed $\mathrm{OH}$. radicals and subsequently combined into long-lived species $\left(\mathrm{H}_{2} \mathrm{O}_{2}\right)$, which played an important role in the AuNPs synthesis:

$$
\begin{gathered}
\mathrm{e}_{\text {gas }}^{-}+\mathrm{H}_{2} \mathrm{O} \rightarrow \mathrm{H}^{-}+\mathrm{OH} \\
\mathrm{OH} \cdot+\mathrm{OH} \cdot \rightarrow \mathrm{H}_{2} \mathrm{O}_{2} .
\end{gathered}
$$




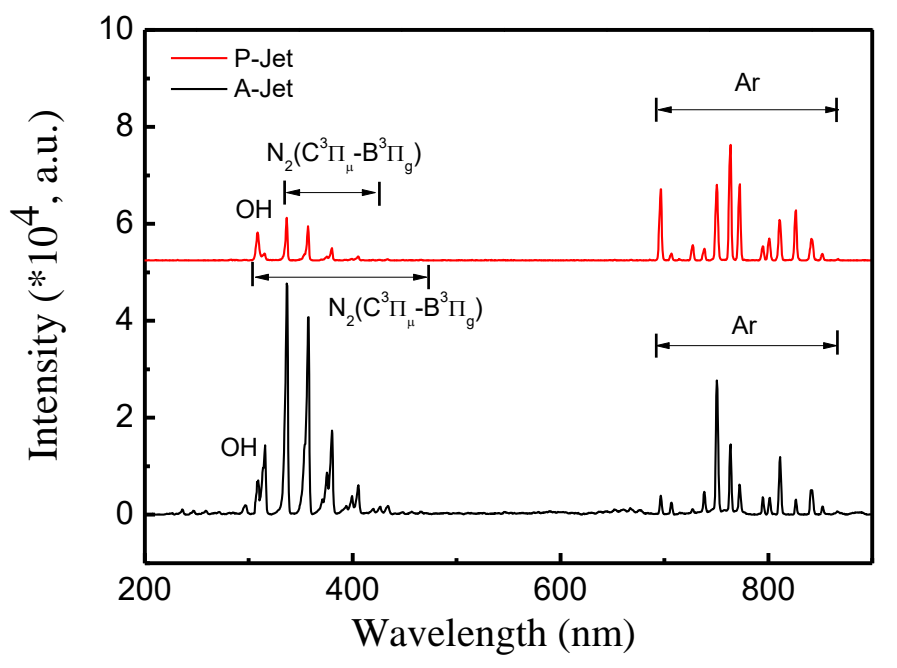

Figure 10. Optical emission spectra of the A-Jet and P-Jet near the liquid surface.

However, the $\mathrm{H}$ radical was not detected in both cases, which confirmed that water decomposition into the atomic $\mathrm{H}$ and $\mathrm{OH}$. radical pathway was not dominant in our experiments. The presence of the $\mathrm{N}_{2}$ second positive system was caused by excitation, quenching processes, associative excitation, pooling reactions, transfer of energy between collisional partners, Penning excitation [26], etc. The $\mathrm{N}_{2}$ species were then combined into $\mathrm{NO}_{3}{ }^{-}$and $\mathrm{NO}_{2}{ }^{-}$long-lived species in the liquid. Although the energy of metastable-state $\mathrm{Ar}$ is lower than the threshold excitation energy of $\mathrm{O}_{2}(13.6 \mathrm{eV})$, metastable-state $\mathrm{Ar}$ can dissociate oxygen molecules and excite the state by Penning excitation. However, the $\mathrm{O}$ emission lines were not detected due to their low intensity.

Furthermore, the liquid chemistry was studied by measuring the conductivity, $\mathrm{pH}$ value, and $\mathrm{Cl}^{-}$concertation. The applied voltage for the A-Jet was kept at $6.4 \mathrm{kV}$, and it was $8 \mathrm{kV}$ for the P-Jet in these experiments, unless otherwise specified. As shown in Figure 11a, the $\mathrm{pH}$ value decreased almost linearly with the increase of the plasma treatment time, while the conductivity showed the opposite tendency. After AC plasma treatment for $150 \mathrm{~s}$, the $\mathrm{pH}$ value decreased from 6.32 to 5.36, while the conductivity increased from 396 to $500 \mu \mathrm{s} / \mathrm{cm}$. With the pulsed power plasma treatment, the $\mathrm{pH}$ value and conductivity showed a tendency similar to the AC plasma jet, but with a smaller change. For example, after $11 \mathrm{~min}$ of treatment, the $\mathrm{pH}$ decreased from 6.32 to 5.78 , and the conductivity increased from 396 to $462 \mu \mathrm{s} / \mathrm{cm}$. The slower changes of $\mathrm{pH}$ and conductivity in the P-Jet compared with the A-Jet were consistent with its slower AuNP generation rate. A similar evolution of $\mathrm{pH}$ and conductivity was observed in discharges generated above the water surface [27]. The changes in $\mathrm{pH}$ and conductivity may be attributed to the water hydrolysis initiated by electrons or reactive species generated by the plasma jet [28]. Water hydrolysis produced $\mathrm{H}^{+}$and led to a decreased $\mathrm{pH}$ value during the reaction:

$$
2 \mathrm{H}_{2} \mathrm{O}-4 \mathrm{e}^{-} \rightarrow \mathrm{O}_{2} \uparrow+4 \mathrm{H}^{+} .
$$

In addition, the reduction of $\mathrm{Au}^{3+}$ by $\mathrm{H}_{2} \mathrm{O}_{2}$ consumed $\mathrm{OH}^{-}$:

$$
3 \mathrm{H}_{2} \mathrm{O}_{2}+3 \mathrm{OH}^{-}+\mathrm{Au}^{3+} \rightarrow \mathrm{Au}^{0}+3 \mathrm{HO}_{2}+3 \mathrm{H}_{2} \mathrm{O} .
$$



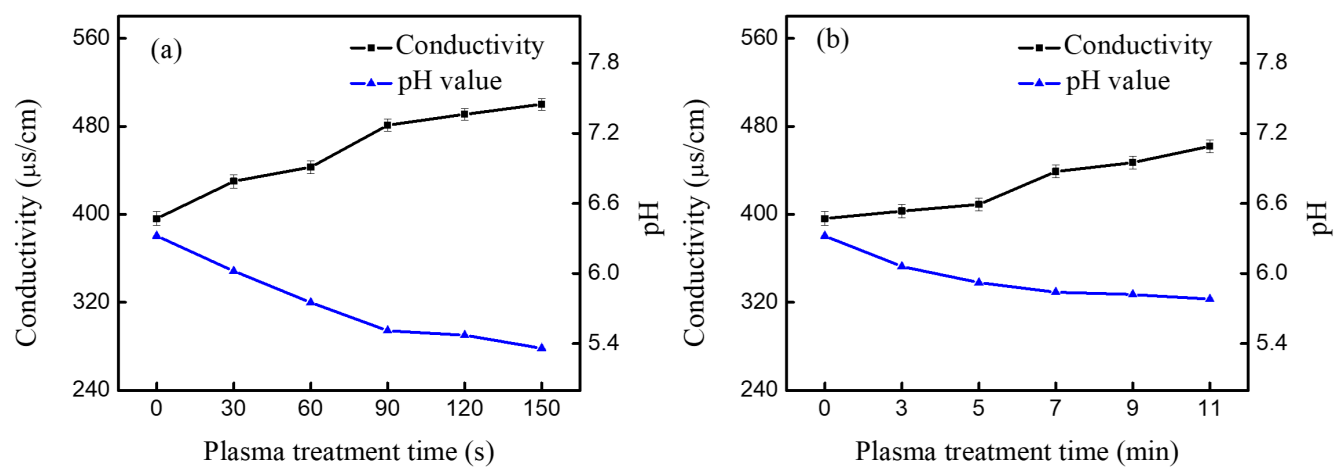

Figure 11. The conductivity and $\mathrm{pH}$ value of the mixture solution after plasma reaction: (a) A-Jet for $90 \mathrm{~s}$ (voltage: $6.4 \mathrm{kV}$, frequency: $90 \mathrm{kHz}$ ) and (b) P-Jet for $7 \mathrm{~min}$ (voltage: $8 \mathrm{kV}$, frequency: $8 \mathrm{kHz}$ ).

The $\mathrm{pH}$ variation in the solution was essential for AuNP diameter control. In the first state, the reduction of $\mathrm{AuCl}^{-}$by plasma formed a loose self-assembly (100 nm or more) of small $\mathrm{Au}$ nanoclusters (less than $1 \mathrm{~nm}$ ) [29]. With the $\mathrm{pH}$ drop in the solution, the self-assembly of $\mathrm{Au}$ nanoclusters disassembled into smaller sizes than the previous assembly. Because at low $\mathrm{pH}$ values, the self-assembly of Au nanoclusters are easy to disassemble. This explains why AuNP presented a much larger size when generated by P-Jet compared with the A-Jet. As confirmed by the optical emission spectra, newly generated $\mathrm{NO}_{3}{ }^{-}, \mathrm{NO}_{2}{ }^{-}$, and $\mathrm{Cl}^{-}$long-lived species cascaded by $\mathrm{N}_{2}$ species might have been responsible for the conductivity increase in the liquid.

Figure 12 shows the $\mathrm{Cl}^{-}$and $\mathrm{H}_{2} \mathrm{O}_{2}$ concentrations as treatment time increased for the A-Jet (a) and P-Jet (b). After plasma treatment, the $\mathrm{H}_{2} \mathrm{O}_{2}$ concentration was $0.56 \mathrm{mM}$ for the A-Jet (reaction time: $150 \mathrm{~s}$ ) and $0.59 \mathrm{mM}$ for the P-Jet (reaction time: $11 \mathrm{~min}$ ). Although the $\mathrm{H}_{2} \mathrm{O}_{2}$ concentration for the A-Jet and P-Jet processes reached almost the same value, clearly, the $\mathrm{H}_{2} \mathrm{O}_{2}$ production rate was much faster in the A-Jet process. The growth of $\mathrm{Cl}^{-}$concentration was even faster in the A-Jet process. After a reaction time of $150 \mathrm{~s}$, the $\mathrm{Cl}^{-}$concentration reached $1.1 \mathrm{mM}$, while the $\mathrm{Cl}^{-}$concentration was $0.4 \mathrm{mM}$ in the P-Jet process after $11 \mathrm{~min}$ of reaction. These results proved that the strong chemical reactions involved in the A-Jet were responsible for its faster growth rate of AuNP.
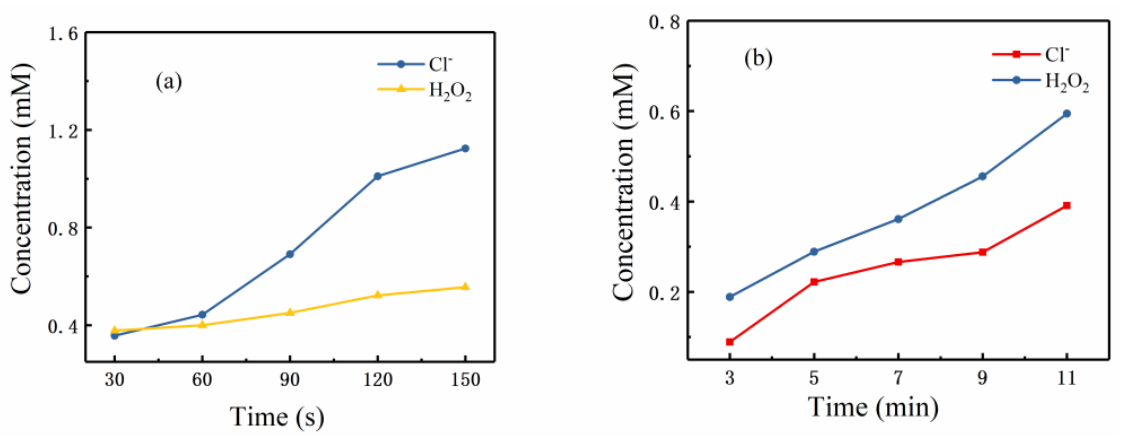

Figure 12. $\mathrm{Cl}^{-}$and $\mathrm{H}_{2} \mathrm{O}_{2}$ generation in the (a) A-Jet and (b) P-Jet cases.

\subsection{The Role of Electrons and Neutral Species}

The generation of AuNP initiated the reduction of metal ions $\left(\mathrm{Au}^{+}\right)$in the solution either by electrons or neutral species. In the liquid cathode case [22], the Ar ions driven by the voltage fall attached to the liquid surface, creating some secondary effects, such as the generation of secondary electrons. The dissolved secondary electrons had a strong reducing ability for AuNP synthesis [30]. However, in our experiments, without a noble anode in the liquid, the voltage drop could be neglected, and the role of electron reduction could have been suppressed. To verify our assumption, a square copper grid with a diameter of $4 \times 4 \mathrm{~cm}$ was placed above reaction cell $\mathrm{A}$, and the copper grid was connected to a copper wire in cell B. So, only the electrons or ions could flux into cell B, while other 
reactive species were transported into cell $\mathrm{A}$, and the effect of neutral species was studied. The schematic diagram of the experimental setup is shown in Figure 13. The validation of this experimental setup was proved in [31]. Cell C, which did not have a copper grid and wire, was studied as the control group.

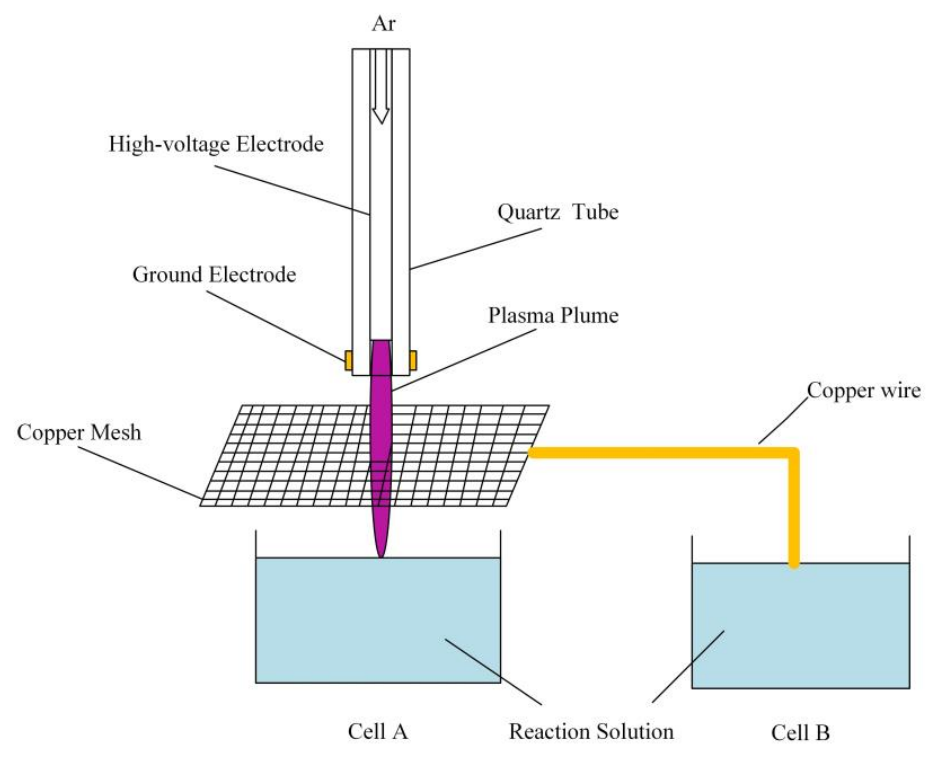

Figure 13. Schematic diagram of the experimental setup.

Figure 14 shows the UV-Vis spectra in these three cells after plasma treatment for different times (90 s for A-Jet and $7 \mathrm{~min}$ for P-Jet). Compared with cell C, cell B showed a red-shift absorption peak and a lower peak intensity. There were no absorption peaks detected in cell $\mathrm{A}$, which confirmed that electron reduction alone was not dominant in our experiments. Visual observation indicated the same trend: the color of the AuNP changed from red-purple to dark-purple in the A-Jet case and changed from dark-purple to shallow pink. Cell A showed no color changes in both cases. These results also confirmed that the electrons and neutral species had a notable synergetic effect on AuNP synthesis, causing a higher absorption intensity in cell C.
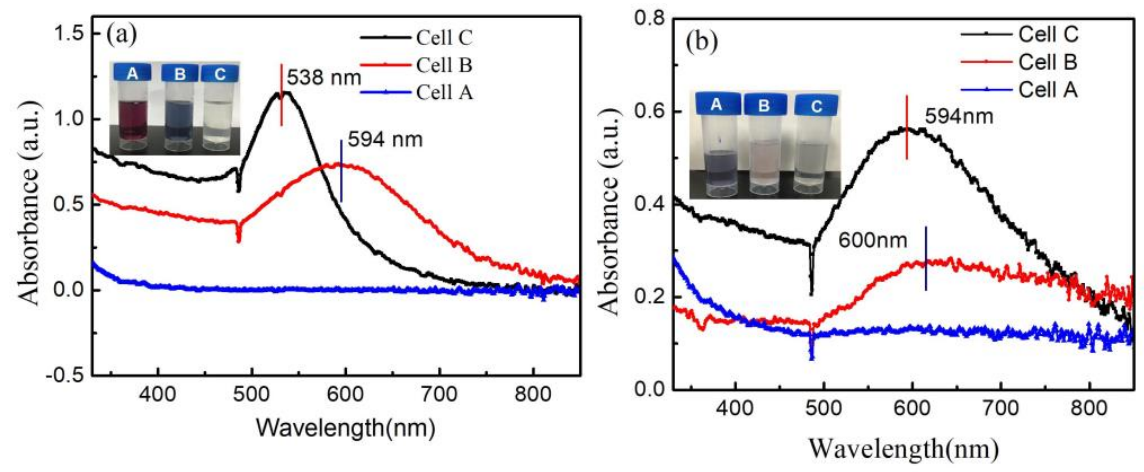

Figure 14. UV-Vis absorption spectra of AuNP for cells A-C with the interaction of (a) the A-Jet and (b) the P-Jet (A, B, and C in the vials stands for Cell A, Cell B and Cell C).

As shown in Figure 15a, the variation of the $\mathrm{pH}$ value in Cell A, B, and C was 6.15, 6.27, and 5.51 for the A-Jet and 6.07, 6.31, and 5.84 for the P-Jet, respectively. This confirmed that the electrons transferred to the liquid had little effect on $\mathrm{pH}$ value changes. In cell $\mathrm{A}$, the $\mathrm{pH}$ value reduced to 6.15 and 6.07 for the A-Jet and the P-Jet, respectively. The combination of natural species and electrons resulted in a maximum $\mathrm{pH}$ value reduction of 5.51 and 5.84 for the A-Jet and the P-Jet, respectively. 
Similar phenomena were observed for the conductivity measured in the three cells. An increase in conductivity was only observed in cells $A$ and $C$. These results were consistent with the UV-Vis absorption spectra.
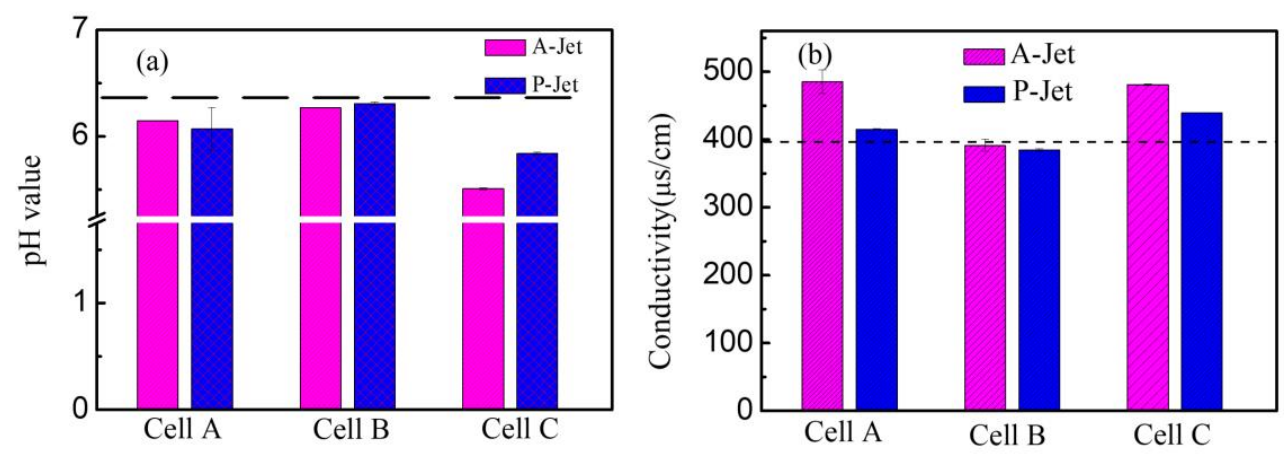

Figure 15. The conductivity and $\mathrm{pH}$ value of the different cells at: (a) A-Jet for $90 \mathrm{~s}$ (voltage: $6.4 \mathrm{kV}$, frequency: $90 \mathrm{kHz}$ ) and (b) P-Jet for $7 \mathrm{~min}$ (voltage: $8 \mathrm{kV}$, frequency: $8 \mathrm{kHz}$ ). The dashed line represents the initial $\mathrm{pH}$ value or conductivity of the mixture without plasma treatment.

\section{Discussions}

\subsection{Chemical Reactions for AuNP Generation}

In the plasma-liquid interaction, chemical reactions typically occurred in the gas phase, the gas-liquid interface, and the liquid phase simultaneously. In the gas phase, plasma ignition generated high-energy electrons, reactive species, and UV. These species subsequently dissolved in the water and had a major role in influencing the final liquid chemistry [32]. As confirmed by optical emission spectroscopy (Figure 10), excited $\mathrm{Ar}, \mathrm{OH} \cdot$, and $\mathrm{N}_{2}\left(C^{3} \Pi_{\mu}-B^{3} \Pi_{g}\right)$ were directly observed. Under a certain amount of pressure provided by Ar gas, there was a thin layer of water steam above the bulk liquid. The transportation of ions, electrons, and neutral species went through the plasma-liquid interface to the bulk liquid. In this region, the recombination, absorption, or desorption of reactive species and solvation of electrons or ions occurred [33], for example, the formation of hydrogen peroxide by hydroxyl radical recombination $\left(2 \mathrm{OH}_{(\text {int })} \rightarrow \mathrm{H}_{2} \mathrm{O}_{2(\text { int })}\right)$, followed by incorporation of the hydrogen peroxide into the liquid $\left(\mathrm{H}_{2} \mathrm{O}_{2}(\right.$ int $\left.) \rightarrow \mathrm{H}_{2} \mathrm{O}_{2(a q)}\right)$. For ions or low-energy electrons, they were mostly immediately solvated when striking the liquid. The simulations showed that even $100 \mathrm{eV} \mathrm{O}^{+}$ions do not penetrate beyond the liquid surface by more than $3 \mathrm{~nm}$ [34]. As for high-energy electrons, the excitation, dissociation, or ionization of water molecules was expected. Solvated electrons (or hydrated electrons) can hydrolyze water by the following reactions:

$$
\begin{gathered}
2 \mathrm{e}_{(\mathrm{aq})}^{-}+2 \mathrm{H}_{2} \mathrm{O} \rightarrow \mathrm{H}_{2(\mathrm{~g})}+2 \mathrm{OH}^{-}, \\
2 \mathrm{e}_{(\mathrm{aq})}^{-}+2 \mathrm{H}^{+} \rightarrow \mathrm{H}+2 \mathrm{OH}^{-} .
\end{gathered}
$$

Electrolytic reactions between plasma electrons and aqueous ions yield an excess of hydroxide ions $\left(\mathrm{OH}^{-}\right)$, making the solution more basic, while reactions between reactive neutral species formed in the plasma phase and the solution lead to nitrous acid $\left(\mathrm{HNO}_{2}\right)$, nitric acid $\left(\mathrm{HNO}_{3}\right)$, and hydrogen peroxide $\left(\mathrm{H}_{2} \mathrm{O}_{2}\right)$, making the solution more acidic [35]. According to our results, the $\mathrm{pH}$ value decreased rather than increased, confirming that the latter process dominated.

In the bulk liquid, the reduction of $\mathrm{AuCl}^{-}$by a reductant agent $\left(\mathrm{H}_{2} \mathrm{O}_{2}\right.$, hydrated electrons) occurred. In general, reduction by both long-lived species (e.g., $\mathrm{H}_{2} \mathrm{O}_{2}$ ) and electrons was considered very important, but it is unclear if one was dominant. By putting a copper mesh over the reaction cell, the role of electrons and neutral species was studied. With electrons, there was no AuNP generation, while neutral species induced visible color changes with plasma treatment, confirming that the neutral species played a more important role for AuNP synthesis. It is interesting to note that there was a 
unique coupling effect between both reactions. This is because the generation of AuNP also requires a moderate $\mathrm{pH}$ value and conductivity. The complex processes of plasma-liquid chemistry for AuNP synthesis is shown in Figure 16.

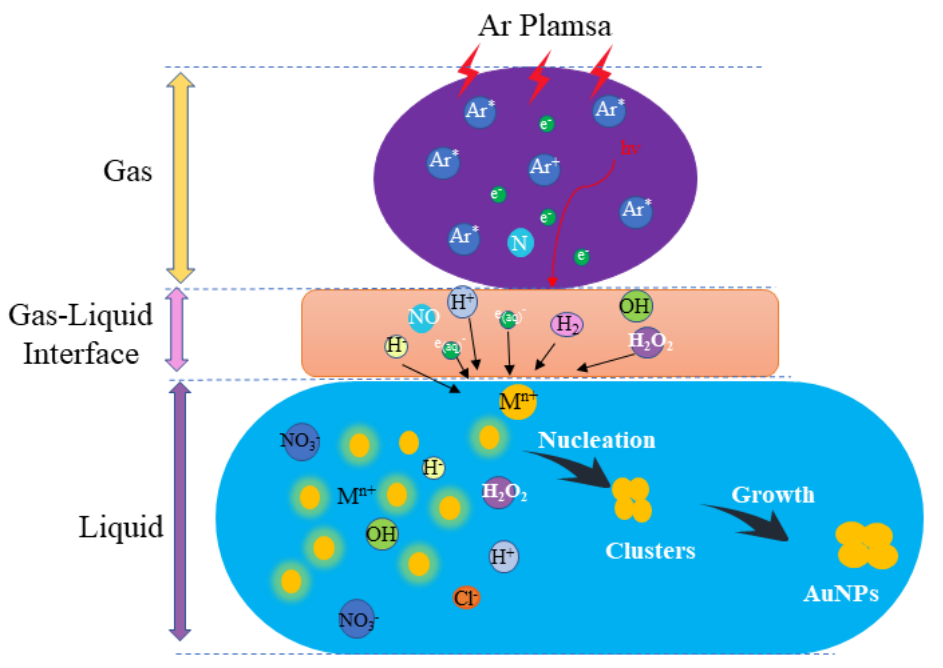

Figure 16. Schematic diagram of the synthesis mechanisms for plasma-liquid interaction.

\subsection{The Effect of A-Jet and P-Jet}

The breakdown mechanisms for the A-Jet and the P-Jet are different. For the A-Jet, filament discharge was observed, as confirmed by the waveform of the discharge current shown in Figure 2. Since the excitation voltage is a continuous sine AC wave voltage, the directional movement of ions cannot be neglected, which means the working gas can be heated by positive ions and neutral particles [36]. For the P-Jet, with the narrow pulse duration and short pulse rising time, the electrical energy was consumed to generate energetic electrons during discharge instead of heating plasma gas. The electron energy in P-Jet was higher than that of A-Jet. During one pulse discharge period, a short discharge duration time (about $200 \mathrm{~ns}$, including positive and negative discharges) and a long discharge period (about $1.25 \times 10^{8} \mathrm{~ns}$ ) guaranteed that there was enough time for the plasma to cool down sufficiently. Thus, a prime difference between A-Jet and P-Jet was their different electron energy and gas temperature. As proved by many studies, the gas temperature of an A-Jet is always higher than that of a P-Jet. The temperature of a P-Jet can remain at room temperature, while an A-Jet can reach $100{ }^{\circ} \mathrm{C}$ in similar conditions [34]. During the reaction process, plasma directly touches with the liquid surface, and the reaction occurs mainly around this region. As is known, the reaction temperature is essential for AuNP synthesis, and a higher reaction temperature is beneficial for a higher reaction rate. So, the AuNP growth rate observed here was much higher in the A-Jet $(0.4 \mathrm{mg} / \mathrm{s})$ than in the P-Jet $(9.5 \mu \mathrm{g} / \mathrm{s})$. Due to the small diameter of the quartz tubing (the plasma was focused at a very small area of about $1.3 \times 10^{-2} \mathrm{~cm}^{-2}$ ) and the short reaction time (especially for the A-Jet), the bulk liquid temperature has little changes. Although P-Jet favors a higher electron energy, as we confirmed in Section 3.4, the electron alone has a minor role in $\mathrm{Au}^{+}$reduction.

Another consideration is the discharge power. With a short pulse rise time (50 ns), plasma is excited at a high overvoltage. In principle, more highly energetic electrons are produced in P-plasma. However, here, due to the short pulse duration time and small pulse frequency, the input power and energy of the P-Jet was only half that of the A-Jet. As we explained in Section 4.1, the electrons alone had little effect on $\mathrm{Au}^{+}$reduction. Instead, the concentration of $\mathrm{Cl}^{-}$and $\mathrm{H}_{2} \mathrm{O}_{2}$ were much higher in the A-Jet, and $\mathrm{H}_{2} \mathrm{O}_{2}$ can be the main reducing agent for $\mathrm{Au}^{+}$. The higher concentration of $\mathrm{Cl}^{-}$was beneficial for the $\mathrm{pH}$ drop, which thus enhanced the dissociation of Au nanoclusters, resulting in a smaller AuNP diameter. 


\section{Conclusions}

In this study, aqueous AuNP were successfully generated by A-Jet and P-Jet, respectively. Different AuNP synthesis processes were observed: (1) faster AuNP growth rate for the A-Jet (more than 40 times faster than the P-Jet) and (2) narrower AuNP size distribution and a broader size control range in the A-Jet case compared to P-Jet case. Further analysis revealed an increase in chemical concentrations $\left(\mathrm{Cl}^{-}\right.$and $\left.\mathrm{H}_{2} \mathrm{O}_{2}\right)$ and conductivity after plasma treatment and a higher increased amplitude in the A-Jet case. In addition, the $\mathrm{pH}$ value decreased during the reaction. The differences between the A-Jet and the P-Jet were due to their different discharge mechanisms: the local heating and higher discharge power in the A-Jet were very important for AuNP generation. Finally, by putting a copper mesh over the reaction cell, the roles of electrons and neutral species were studied. With electrons, there was no AuNP generation, while neutral species (e.g., $\mathrm{OH} \cdot$ ) induced visible color changes with plasma treatment. The long-lived species (e.g., $\mathrm{H}_{2} \mathrm{O}_{2}$, combined by $\mathrm{OH}$.) was responsible for $\mathrm{Au}^{3+}$ reducing and played a more important role in AuNP synthesis.

Author Contributions: Conceptualization, R.W. and X.L.; methodology, P.X. and Y.Q.; resources, J.W.; writing - original draft, R.W. and X.L.

Funding: This research was funded by [National Natural Science Foundation of China] grant number $[51,877,205]$ And by [State Key Laboratory of NBC Protection for Civilians] grant number [JH05-2019-01].

Conflicts of Interest: The authors declare no conflict of interest.

\section{References}

1. Ma, Y.; Huang, Z.; Li, S.; Zhao, C. Surface-Enhanced Raman Spectroscopy on Self-Assembled Au Nanoparticles Arrays for Pesticides Residues Multiplex Detection under Complex Environment. Nanomaterials 2019, 9, 426. [CrossRef] [PubMed]

2. Mahan, M.M.; Doiron, A.L. Gold Nanoparticles as X-Ray, CT, and multimodal imaging contrast agents: Formulation, targeting, and methodology. Nanomaterials 2018, 15, 5837276. [CrossRef]

3. Roya, B.; Hassan, H.; Hossein, F.; Farid, H.H.; Fatemeh, A.; Seyedeh, Z.M. In situ generation of the gold nanoparticles-bovine serum albumin (AuNPs-BSA) bioconjugated system using pulsed-laser ablation (PLA). Mater. Chem. Phys. 2016, 177, 360-370.

4. Guo, Z.X.; Zhang, M.; Zhao, L.B.; Guo, S.S.; Zhao, X.Z. Generation of alginate gel particles with AuNPs layers by polydimethylsiloxan template. Biomicrofluidics 2011, 5, 026502. [CrossRef] [PubMed]

5. Peng, C.F.; Duan, X.H.; Xie, Z.J.; Liu, C.L. Shape-controlled generation of gold nanoparticles assisted by dual-molecules: The development of hydrogen peroxide and oxidase-based biosensors. J. Nanomater. 2014, 7, 576082. [CrossRef]

6. Chen, Q.; Li, J.; Li, Y. A review of plasma-liquid interactions for nanomaterial synthesis. J. Phys. D 2015, 48, 424005. [CrossRef]

7. Wang, S.; Qian, K.; Bi, X.Z.; Huang, W. Influence of Speciation of Aqueous $\mathrm{HAuCl}_{4}$ on the synthesis, structure, and property of Au colloids. J. Phys. Chem. C 2009, 113, 6505-6510. [CrossRef]

8. Genki, S.; Tomohiro, A. Nanomaterial synthesis using plasma generation in liquid. J. Nanomater. 2015, 2015, 123696.

9. Wang, R.; Zuo, S.; Zhu, W.; Zhang, J.; Fang, J. Rapid synthesis of aqueous-phase magnetite nanoparticles by atmospheric pressure non-thermal microplasma and their application in magnetic resonance imaging. Plasma Process. Polym. 2014, 11, 448-454. [CrossRef]

10. Patel, J.; Nemcova, L.; Maguire, P.; Graham, W.G.; Mariotti, D. Synthesis of surfactant-free electrostatically stabilized gold nanoparticles by plasma-induced liquid chemistry. Nanotechnology 2013,24, 245604. [CrossRef]

11. Hattori, Y.; Nomura, S.; Mukasa, S.; Toyota, H.; Inoue, T.; Usui, T. Synthesis of tungsten oxide, silver, and gold nanoparticles by radio frequency plasma in water. J. Alloy. Compd. 2013, 578, 148-152. [CrossRef]

12. Jiang, N.; Hu, J.; Li, J.; Shang, K.F.; Lu, N.; Wu, Y. Plasma-catalytic degradation of benzene over Ag-Ce bimetallic oxide catalysts using hybrid surface/packed-bed discharge plasmas. Appl. Catal. B 2016, 184, 355-3635. [CrossRef] 
13. Maguire, P.; Rutherford, D.; Montero, M.M.; Mahony, C.; Kelsey, C.; Weedie, M.T.; Martin, F.P.; Mcquid, H.; Diver, D.; Mariotti, D. Continuous In-Flight Synthesis for On-Demand Delivery of Ligand-Free Colloidal Gold Nanoparticles. Nano Lett. 2017, 17, 1336-1343. [CrossRef] [PubMed]

14. Meiss, S.A.; Rohnke, M.; Kienle, L.; Zein El Abedin, S.; Endres, F.; Janek, J. Employing plasmas as gaseous electrodes at the free surface of ionic liquids: Deposition of nanocrystalline silver particles. J. Chem. Phys. Chem. 2007, 8, 50-53. [CrossRef]

15. Kaneko, T.; Baba, K.; Hatakeyama, R. Gas-liquid interfacial plasmas: Basic properties and applications to nanomaterial synthesis. Plasma Phys. Controll. Fusion 2009, 51, 124011. [CrossRef]

16. Wu, S.; Wu, F.; Liu, C.; Liu, X.; Chen, Y.; Shao, T.; Zhang, C. The effects of the tube diameter on the discharge ignition and the plasma properties of atmospheric-pressure micro plasma confined inside capillary. Plasma Process. Polym. 2019, 16, 1800176. [CrossRef]

17. Wang, Y.Q.; Yu, F.; Zhu, M.Y.; Ma, C.H.; Zhao, D.; Wang, C.; Zhou, A.M.; Dai, B.; Ji, J.Y.; Guo, X.H. N-Doping of plasma exfoliated graphene oxide via dielectric barrier discharge plasma treatment for the oxygen reduction reaction. J. Mater. Chem. A 2018, 6, 2011-2017. [CrossRef]

18. Di, L.B.; Zhan, Z.B.; Zhang, X.L.; Qi, B.; Xu, W.J. Atmospheric-Pressure DBD Cold Plasma for Preparation of High Active Au/P25 Catalysts for Low-Temperature CO Oxidation. Plasma Sci. Technol. 2016, 18, 544-548. [CrossRef]

19. Wang, R.; Zhang, C.; Shen, Y.; Zhu, W.; Yan, P.; Shao, T.; Babaeva, N.Y.; Naidis, G.V. Temporal and spatial profiles of emission intensities in atmospheric pressure helium plasma jet driven by microsecond pulse: Experiment and simulation. J. Appl. Phys. 2015, 118, 123303.

20. Wang, R.; Zhang, K.; Shen, Y.; Zhang, C.; Zhu, W.; Shao, T. Effect of pulse polarity on the temporal and spatial emission of an atmospheric pressure helium plasma jet. Plasma Sources Sci. Technol. 2016, 25, 015020. [CrossRef]

21. Konesky, G. Dwell time considerations for large area cold plasma decontamination. Proc. SPIE 2009, 7304, 73040N-73041N.

22. Wang, R.; Gao, Y.; Zhang, C.; Yan, P.; Shao, T. Dynamics of plasma bullets in a microsecond-pulse driven atmospheric pressure He plasma jet. IEEE Trans. Plasma Sci. 2016, 4, 393-397. [CrossRef]

23. Patrick, V.; Anton, N.; Annemie, B.; Christophe, L. Study of an AC dielectric barrier single micro-discharge filament over a water film. Sci. Rep. 2018, 8, 10919.

24. Shao, T.; Wang, R.; Zhang, C.; Yan, P. Atmospheric-pressure pulsed discharges and plasmas: Mechanism, characteristics and application. High Volt. 2018, 3, 14-20. [CrossRef]

25. Wang, R.; Zuo, S.; Wu, D.; Zhang, J.; Zhu, W.; Becker, K.H.; Fang, J. Micro plasma-assisted synthesis of colloidal gold nanoparticles and their use in the detection of cardiac troponin I (cTn-I). Plasma Process. Polym. 2015, 12, 380-391. [CrossRef]

26. Wang, R.; Sun, H.; Zhu, W.; Zhang, C.; Zhang, S.; Shao, T. Uniformity optimization and dynamic studies of plasma jet array interaction in argon. Phys. Plasmas 2017, 24, 093507. [CrossRef]

27. Liu, Y.; Zhang, H.; Sun, J.; Liu, J.; Shen, X.; Zhan, J.; Zhang, A.; Ogniger, S.; Cavadias, S.; Li, P. Degradation of aniline in aqueous solution using non-thermal plasma generated in microbubbles. Chem. Eng. J. 2018, 345, 679-687. [CrossRef]

28. Dang, T.H.; Denat, A.; Lesaint, O.; Teissedre, G. Degradation of organic molecules by streamer discharges in water: Coupled electrical and chemical measurements. Plasma Sources Sci. Technol. 2008, 17, 024013. [CrossRef]

29. Saito, N.; Hieda, J.; Takai, O. Synthesis process of gold nanoparticles in solution plasma. Thin Solid Film. 2009, 518, 912-917. [CrossRef]

30. Hart, E.J.; Anbar, M. The Hydrated Electron; Wiley: New York, NY, USA, 1970; Volume 276, p. 5126764.

31. Chen, Z.; Liu, D.; Xu, H.; Xia, W.; Liu, Z.; Xu, D.; Rong, M.; Kong, G. Decoupling analysis of the production mechanism of aqueous reactive species induced by a helium plasma jet. Plasma Sources Sci. Technol. 2019, 28, 025001. [CrossRef]

32. Tani, A.; Ono, Y.; Fukui, S.; Ikawa, S.; Kitano, K. Free radicals induced in aqueous solution by non-contact atmospheric-pressure cold plasma. Appl. Phys. Lett. 2012, 100, 254103. [CrossRef]

33. Bruggeman, P.J.; Kushner, M.J.; Locke, B.R.; Gardeniers, J.G.; Graham, W.G.; Graves, D.B.; Hofman-Caris, R.C.; Maric, D.; Reid, J.P.; Ceriani, E.; et al. Plasma-liquid interactions: A review and roadmap. Plasma Sources Sci. Technol. 2016, 25, 053002. [CrossRef] 
34. Minagawa, Y.; Shirai, N.; Uchida, S.; Tochikubo, F. Analysis of effect of ion irradiation to liquid surface on water molecule kinetics by classical molecular dynamics simulation. Jpn. J. Appl. Phys. 2014, 53, 010210. [CrossRef]

35. Rumbach, P.; Witzke, M.; Sankaran, R.M.; Go, D.B. Decoupling interfacial reactions between plasmas and liquids: Charge transfer vs plasma neutral reactions. J. Am. Chem. Soc. 2013, 135, 16264-16267. [CrossRef] [PubMed]

36. Zhang, L.; Yang, D.; Wang, W.; Wang, S.; Yuan, H.; Zhao, Z.; Sang, C.; Jia, L. Needle-array to plate DBD plasma using sine AC and nanosecond pulse excitations for purpose of improving indoor air quality. Sci. Rep. 2016, 6, 25242. [CrossRef]

(C) 2019 by the authors. Licensee MDPI, Basel, Switzerland. This article is an open access article distributed under the terms and conditions of the Creative Commons Attribution (CC BY) license (http://creativecommons.org/licenses/by/4.0/). 